\title{
Characterization of large area flexible plastic solar cells based on conjugated polymer/fullerene composites
}

\author{
Desta Gebeyehu, ${ }^{1}$ F. Padinger, ${ }^{2}$ C. J. Brabec, ${ }^{1}$ T. Fromherz, ${ }^{2}$ \\ J. C. Hummelen, ${ }^{3}$ and N. S. Sariciftci ${ }^{1}$ \\ ${ }^{1}$ Christian Doppler Laboratory for Plastic Solar Cells, Physical Chemistry, \\ Johannes. Kepler University of Linz, Altenbergerstr. 69, A-4040 Linz, Austria \\ ${ }^{2}$ Quantum Solar Energy Linz, A-4040 Linz, Austria \\ ${ }^{3}$ University of Groningen, 9747 AG Groningen (The Netherlands)
}

\begin{abstract}
The development of solar cells based on composites of organic conjugated semi-conducting polymers with fullerene derivatives can provide a new method in the exploitation of solar energy. Organic solar cells must fulfill the criteria of stability, efficiency and reduction of production costs to find new applications. Specially, the bulk donor-acceptor heterojunctions between conjugated polymers and fullerenes have been successfully utilized for photovoltaic devices with high carrier collection efficiency compared to the devices made from single components. In this work we present measurements of the photovoltaic response of bulk donor-acceptor heterojunction between the conjugated polymer (as a donor, D) poly(3octylthiophene), P3OT and fullerenes, (as acceptor, A), deposited between indium tin oxide and aluminum electrodes. These devices are based on ultrafast, reversible, metastable photoinduced electron transfer and charge separation.

The quality and homogeneity of composite films as well as the choice of the substrates strongly influence the efficiency of the solar cells. One of the most important limiting factors in the performance of this present types of molecular solar cells based on interpenetrating networks of conjugated polymers and fullerene derivatives is the charge carrier transport in the active layer. This transport is driven by the electrical field provided externally by the top and bottom electrodes with different work functions. We present here efficiency and stability studies on large area $(6 \mathrm{~cm} \times 6 \mathrm{~cm})$ flexible plastic solar cells with monochromatic energy conversion efficiency $\eta_{\mathrm{e}}$ about $1.4 \%$ and carrier collection efficiency nearly $20 \%$.
\end{abstract}

\section{INTRODUCTION}

Polymeric materials have technological advantages over conventional inorganic materials in the reduction of production costs by large scale production, the possibility to produce large area flexible devices and the tunability of the electronic bandgap by chemical synthesis. These properties represent major advances in the design of electronic devices. Photoelectric energy conversion efficiencies for different organic solar cells, including small molecules as well as polymeric cells, are typically in the range of $1 \%$. The recently discovered photoinduced electron transfer in solutions and in solid state composites of semi-conducting, conjugated polymers with fullerenes has attracted considerable scientific and technological attention [1,2]. The possibility of utilizing this effect for photovoltaic energy conversion $[3,4]$ has been demonstrated. With the addition of $\mathrm{C}_{60}$ in the conjugated polymer matrix, the primary photoexcitation of the conjugated polymer undergoes an ultrafast electron transfer, and it has been demonstrated that fullerene molecules may serve as efficient electron acceptors in polymeric cells [5]. However, studies of conjugated polymer/fullerene photovoltaic devices showed, that the energy conversion efficiency is limited by the collection of the charges at the electrodes [6]. This inefficient transport of the charge carriers is explained by the necessity of an interpenetrating network and the limited mobility of both car- riers, i.e. holes on the conjugated polymer as well as electrons on the fullerenes.

Since the charge transfer takes place much faster than the radiative and/or non-radiative decay of photoexcitations, the quantum efficiency for charge separation in such D/A blends is near unity. Efficient polymeric photovoltaic solar cells have been made from phase separated composites of soluble conjugated polymers and $\mathrm{C}_{60}$ as well as from phase separated D/A polymer blends. Significant improvement of the relatively low collection efficiency of the D/A bilayer has been achieved by using phase- separated composite materials through control of the phase-separation into an interpenetrating networks of organic donors and acceptors sandwiched between two electrodes with different work functions. High efficiency conversion involves the formation of bicontinuous networks. The performance of such bulk heterojunction devices is remarkably enhanced compared to devices made from single components and bilayer materials with carrier collection efficiency as high as $29 \%$ and power conversion efficiency about 3\% [6-11]. Solar cells with good performance based on the composite poly (2-methoxy-5-( $3^{\prime}, 7^{\prime}$. dimethyloctyloxy)-1,4-phenylene vinylene), MDMO-PPV and 1-(3-methoxycarbonyl)-propyl-1-phenyl-(6,6) $\mathrm{C}_{61}$, PCBM (1:3 weight ratio) have been recently demonstrated [12]. Up to now, the laminated two layer polymeric photovoltaic diodes based on a cyano derivative of poly(p-phenylene vinylene), MEH-CN-PPV, as elec- 
tron acceptor, and a derivative of polythiophene, POPT, as an electron donor, showed the highest efficiencies among this class. The resulting structures provide a short circuit photovoltaic quantum efficiency up to $29 \%$ at optimum wavelength, and an over all energy conversion efficiency of $4.8 \%$ at the peak wavelength [13].

Still now no systematic studies of the influence of oxygen atmosphere on the characteristics of conjugated polymer/fullerene photovoltaic devices are available. The limited stability of the conjugated polymer/fullerene photovoltaic devices under ambient conditions hinders the practical applications. Recent FTIR degradation studies on the composites showed rapid degradation of the conjugated polymer, MDMO-PPV compared to $\mathrm{C}_{60}$ or PCBM under oxygen and light [14]. In other words, conjugated polymers are known to be sensitive to photo-degradation in oxygen containing environment. Therefore, for practical applications, the stability especially of the polymer part of the mixture has to be improved and devices have to be protected.

In this study, we investigate polymeric devices based on the following composites: $\mathrm{P} 3 \mathrm{OT} / \mathrm{C}_{60}$ (1:1 weight ratio), P3OT/(6,6)PCBM monoadduct or multiadduct ( $1: 2$ weight ratio), which is a derivative of $\mathrm{C}_{60}$ with improved solubility in xylene solutions at room conditions are investigated. Devices with fullerene and fullerene derivatives were characterized by $I / V$ measurements under white light and monochromatic light as well as by wavelength dependent photocurrent measurements. From these data power efficiencies were calculated and compared to carrier collection efficiencies (electrons collected per incident photon). In the present study we show also results of stability and controlled degradation experiments performed with the actual mixture used in plastic solar cells.

\section{MATERIALS AND METHODS}

The device configuration and device preparation for polymer photovoltaic cells (and photodetectors) were described in [1]. The photovoltaic devices produced here are composed of four layers as shown in Figure 1.
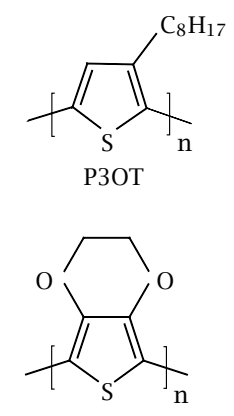

* PEDOT *

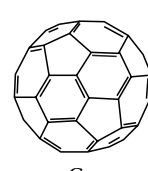

$\mathrm{C}_{60}$

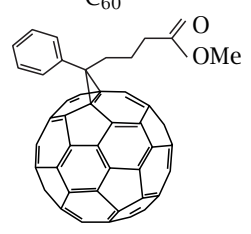

$[6,6] \mathrm{PC}_{61} \mathrm{BM}$

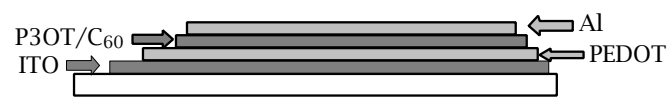

Figure 1. Schematic diagram of the device configuration and molecular structures of the materials used.
First the PEDOT-PSS (poly(3,4-ethylenedioxythiophene)-poly(styrenesulfonate) (Baytron-Bayer AG) was spin coated on ITO (indium tin oxide)-coated polyester substrates i.e. polyethyleneterephtalate (PET) from water solution under ambient conditions with typical areas of $6 \mathrm{~cm}$ by $6 \mathrm{~cm}$. After that the active bulk heterojunction layer was prepared by spin coating films of the composites: $\mathrm{P} 3 \mathrm{OT} / \mathrm{C}_{60}$ ( $1: 1$ weight ratio), P3OT/(6,6)PCBM monoadduct or multiadduct $(1: 2$ weight ratio) on the top of PEDOT-PSS layer. The preparation and characterization of $(6,6)$ PCBM monoadduct, which is a derivative of $\mathrm{C}_{60}$ with improved solubility, is described in [15]. The PCBM multiadduct is a mixture of mono, bis, and tris adducts on the fullerene. After an additional drying step the low work function nontransparent aluminum top electrode was evaporated onto the spin cast film at $5 \times 10^{-5}$ mbar inside the glove box.

All the solar cell devices produced here are in the sandwich geometry as mentioned above between two metal electrodes with different work functions, ITO as anodes (as hole collector) and aluminum as cathode (as electron collector). Asymmetric work functions for the electrodes of organic interpenetrating network photovoltaic devices are necessary for a significant reason. It has been shown that the charge transport between conjugated polymers and fullerenes is favorably tuned by electric field. The electric field due to the different electrodes is the driving force to collect the charges at the electrodes. Without this there will be no selection principle for the holes to travel to the ITO and for the electrons to go to the aluminum electrodes.

To retard the degradation process of plastic solar cells, attempts for the protection have been made. One of the attempts was lamination of the solar cells into special lamination foils. The lamination occurs inside the glove box to avoid oxygen inclusion inside the laminated solar cell. The lamination foils were glued to the cell by heat treatment and measured under ambient conditions. Another attempt was sealing with varnish inside a glove box under nitrogen flow. The cells were kept inside the nitrogen glove box until they are totally dried and afterwards they are stored inside the dissicator under vacuum. For the measurements the solar cells were taken out of the dissicator and measured under room atmosphere (ambient condition). After the measurement they were again stored inside the dissicator under vacuum.

The thickness of semi-conducting organic films represents a crucial parameter for their performance in photovoltaic devices. The need to absorb most of the sunlight in solar cells requires a film thicker than $100 \mathrm{~nm}$. On the other hand, thin layers enhance the internal electric field and improve the charge transport. In our work, the typical film thicknesses are around 100$200 \mathrm{~nm}$ and were monitored by determination of the optical density with a Hitachi spectrometer. The quality and the homogeneity of the composite films strongly influence the efficiency of the solar cell. Inhomogeneous 
films with pin holes and large serial resisitivities lead to small fill factor $(F F)$, lower rectification and decreased the open circuit voltage $\left(V_{\text {oc }}\right)$.

Additional important parameter, determining the quality of thin films is the choice of the substrates. We studied here the $I / V$ characteristics of the conjugated polymer/fullerene composites thin films on ITO polyester substrates with typical area of $6 \mathrm{~cm}$ by $6 \mathrm{~cm}$ and active areas of 4 times $40 \mathrm{~mm}^{2}$.

A defocused $\mathrm{Ar}^{+}$laser beam at $488 \mathrm{~nm}$ provided the illumination and a calibrated Si Photodiode was utilized to measure light intensities. A Keithley SMU 2400 Source Meter was used for recording $I / V$ curves when illuminating the cells through the ITO side, typically by averaging 80 measurements for one point. Optical absorption was obtained with a Hitachi spectrophotometer. Photocurrent excitation profiles were measured using a xenon arc lamp, spectrally resolved by a monochromator, at intensity of $1 \mathrm{~mW} / \mathrm{cm}^{2}$ at each wavelength in the range of between $400 \mathrm{~nm}$ and $800 \mathrm{~nm}$.

\section{RESULTS AND DISCUSSION}

Even though the enhanced solubility of $(6,6) \mathrm{PCBM}$ monoadduct and multiadduct compared to $\mathrm{C}_{60}$ allows to achieve a high fullerene-polymer weight ratio we obtain somewhat smaller short circuit current about $300 \mu \mathrm{A} / \mathrm{cm}^{2}$ compared to short circuit current of $\mathrm{C}_{60}$ nearly $550 \mu \mathrm{A} / \mathrm{cm}^{2}$ under white light source $6 \mathrm{~mW} / \mathrm{cm}^{2}$ inside the glove box. In Figure 2 the influence of fullerene and fullerene derivatives on conjugated polymer, P3OT composites of large area plastic solar cells $I / V$ curves are illustrated.

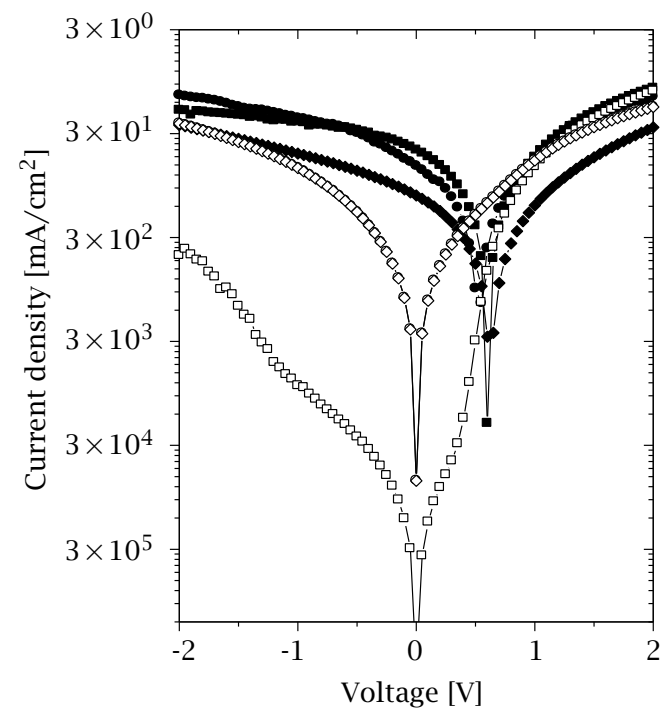

Figure 2. I/V curves of $\mathrm{P} 3 \mathrm{OT}$ large area plastic solar cells for different acceptors: $\mathrm{C}_{60}$ (dark: open squares, illuminated: solid square), PCBM monoadduct (dark: open circles, illuminated: solid circles), and PCBM multiadduct (dark: open diamonds, illuminated: solid diamonds).

The typical data for these flexible large area plastic solar cells are an open circuit voltage $V_{\text {oc }}$ of $550-$
$600 \mathrm{mV}$ and a short circuit current, $I_{\mathrm{sc}}$ of $800 \mu \mathrm{A} / \mathrm{cm}^{2}$ under illumination with $10 \mathrm{~mW} / \mathrm{cm}^{2}$ with an argon laser at $488 \mathrm{~nm}$. Usually the value of the open circuit voltage for the bulk heterojunction devices is interpreted to arise from the work function difference of the two electrodes $(\mathrm{Al}=4.3 \mathrm{eV} ; \mathrm{ITO}=4.7 \mathrm{eV})$ which would yield a $V_{\mathrm{oc}}$ of $400 \mathrm{mV}$ or lower as found by other groups [16,17]. Therefore, the origin of an open circuit voltage as high as $650 \mathrm{mV}$ is not fully understood.

The overall energy conversion efficiency, $\eta_{\mathrm{e}}$, of the flexible plastic solar cell presented here is calculated to be $1.4 \%$ under monochromatic illumination $(488 \mathrm{~nm})$ with $10 \mathrm{~mW} / \mathrm{cm}^{2}$ and a $F F=0.3$. According to the experimental data, typical values for $\eta_{\mathrm{e}}$ are between $1 \%$ and $1.5 \%$. Calculation of $\eta_{\mathrm{e}}$ has been performed using the equation

$$
\eta_{\mathrm{e}}=\left(V_{\mathrm{oc}}[V] * I_{\mathrm{sc}}\left[\mathrm{A} / \mathrm{cm}^{2}\right] * F F\right) / P_{\text {inc }}\left[\mathrm{W} / \mathrm{cm}^{2}\right],
$$

where $V_{\mathrm{oc}}, I_{\mathrm{sc}}, F F$ and $P_{\text {in }}$ are the open circuit potential, short circuit current, filling factor and incident light power, respectively and requires the value of the fill factor $F F$ of the device. We determine the fill factor, $F F$, by calculating the maximum power rectangular area under the $I / V$ curve in the 4 th quadrant. Therefore, the filling factor is calculated by

$$
F F=\left(V_{\max } * I_{\max }\right) /\left(V_{\text {oc }} * I_{\mathrm{sc}}\right),
$$

where $V_{\max }$ and $I_{\max }$ are maximum voltage and current of the intersection of the $I / V$ curve with the maximum power rectangle respectively. The typical $F F$ values for our devices are between 0.27 and 0.33 . For higher illumination intensities $\eta_{\mathrm{e}}$ decreases, but it is still as high as $0.2 \%$ at $176 \mathrm{~mW} / \mathrm{cm}^{2}$.

Figure 3 shows a comparison between the spectrally resolved $I_{\mathrm{sc}}$ (solid circles) plotted at the right axis and the optical density (open circles) at the left axis of a $\mathrm{P} 3 \mathrm{OT} / \mathrm{C}_{60}$ flexible large area plastic solar cell. One can

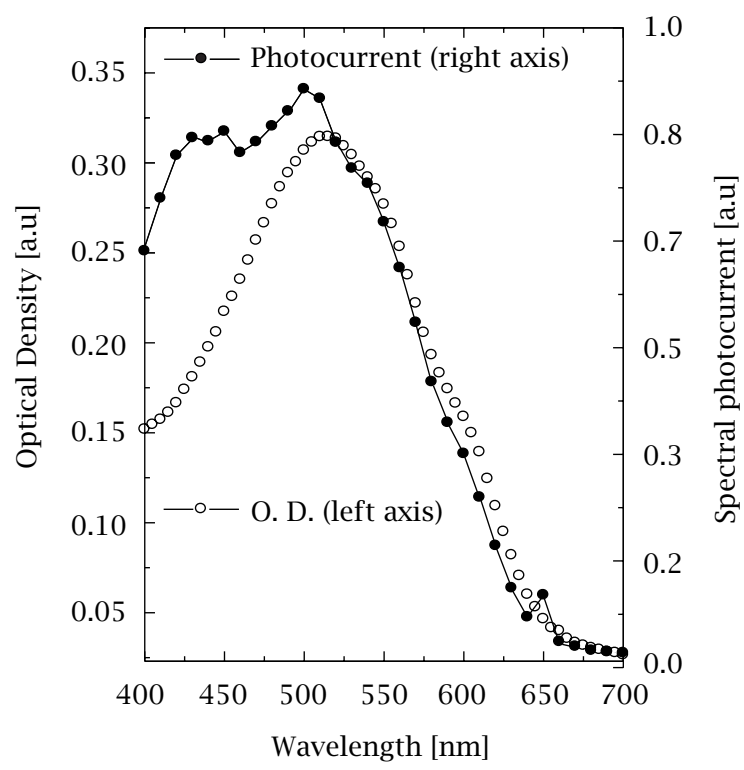

Figure 3. Spectrally resolved $I_{\mathrm{sc}}$ (solid circles) of a P3OT/ $\mathrm{C}_{60}$ flexible large area plastic solar cell (right axis), optical absorption (open circles) is plotted for comparison (left axis). 
see very clearly, that the two curves have the same onset and spectrally resolved maxima separated by only $18 \mathrm{~nm}$. The photovoltaic external quantum efficiency (charge carrier per incident photon) or the spectrally resolved incident photon to electron converted efficiency IPCE $\left(\eta_{\mathrm{c}}\right)$ is calculated from the spectrally resolved short-circuit current $[16,17]$,

$$
\eta_{\mathrm{c}}[\%]=1240 / \lambda[\mathrm{nm}] * I_{\mathrm{sc}}\left[\mu \mathrm{A} / \mathrm{cm}^{2}\right] / I_{\mathrm{inc}}\left[\mathrm{W} / \mathrm{m}^{2}\right],
$$

where $I_{\text {inc }}$ is the intensity of the incident light. We achieved the short circuit photovoltaic external quantum efficiency $\left(\eta_{\mathrm{c}}[\%]\right)=$ about $20 \%$ under an argon laser at $488 \mathrm{~nm}$ with $10 \mathrm{~mW} / \mathrm{cm}^{2}$ and a $I_{\mathrm{sc}}$ of $810 \mu \mathrm{A} / \mathrm{cm}^{2}$.

For practical applications, the stability of plastic solar cells under ambient conditions is one of the most important issues. Therefore, a quick, reliable testing procedure for photodegradation effects in oxygen containing environment is necessary. Figure 4 shows the degradation of a P3OT/ $\mathrm{C}_{60}$ unprotected solar cell monitored by the changes in the $V_{\mathrm{oc}}$ as a function of time under oxygen and white light source with $8 \mathrm{~mW} / \mathrm{cm}^{2}$. After approximately 60 hours $V_{\text {oc }}$ decreases to half of its original value. Figure 5 illustrates the degradations of $I_{\text {sc }}$ unprotected solar cell versus time under white light source $35 \mathrm{~mW} / \mathrm{cm}^{2}$ and oxygen containing environment. As can be seen from measured degradation time, the curve is fitted to an exponential decay and a lifetime of 70 minutes. To retard the degradation process of plastic solar cells, some attempts for the protection have been made. The long term stability of protected plastic solar cells is monitored by $V_{\mathrm{oc}}$ and $I_{\mathrm{sc}}$ measurements under ambient room conditions. In Figure 6 , the $V_{\mathrm{oc}}$ and the $I_{\mathrm{sc}}$ versus shelf lifetime of protected plastic solar cells with varnish are shown. Encapsulation of plastic solar cells increases the shelf lifetime over 100 days. The initial decrease of $V_{\mathrm{oc}}$ and $I_{\mathrm{sc}}$ could be due to the residual oxygen during the cell production process.

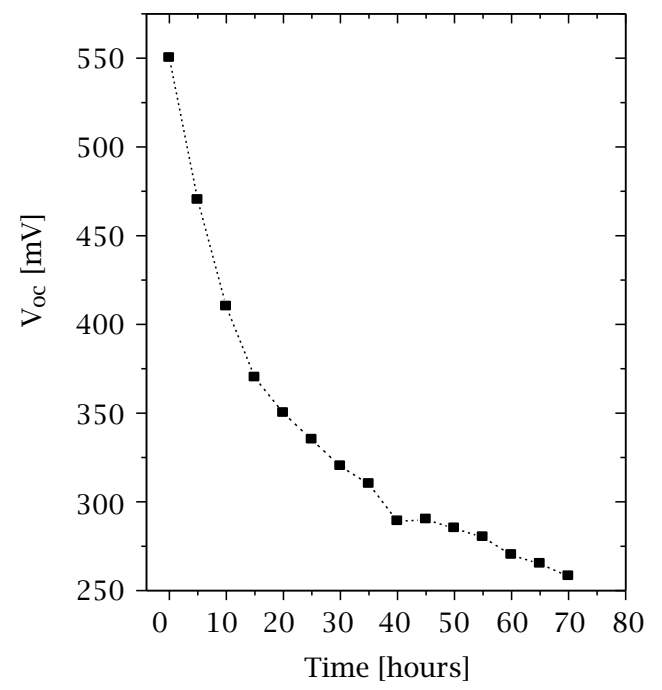

Figure 4. Degradation of $V_{\mathrm{OC}}$ of a $\mathrm{P} 3 \mathrm{OT} / \mathrm{C}_{60}$ unprotected solar cell versus time under bright light and oxygen influence.

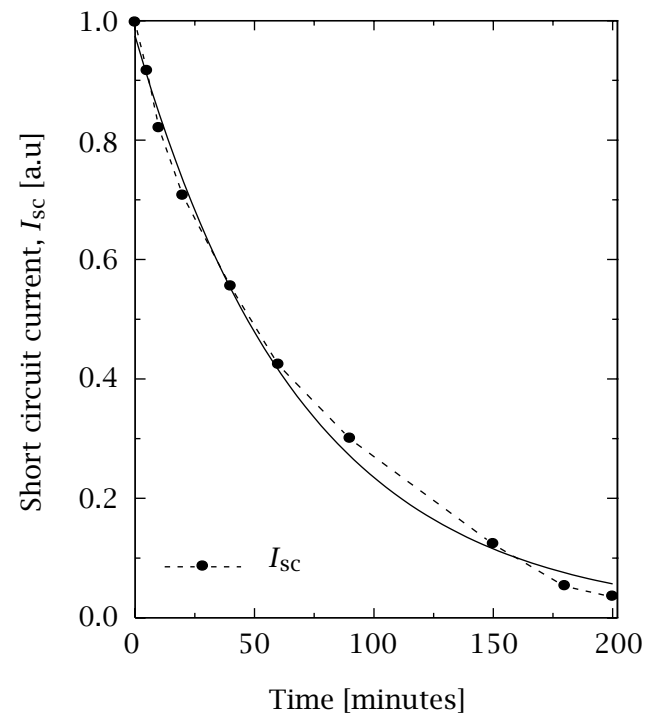

Figure 5. Short circuit current, $I_{\mathrm{sc}}$ degradation vs. time of unprotected $\mathrm{P} 3 \mathrm{OT} / \mathrm{C}_{60}$ plastic solar cell. The curve is fitted to an exponential decay.
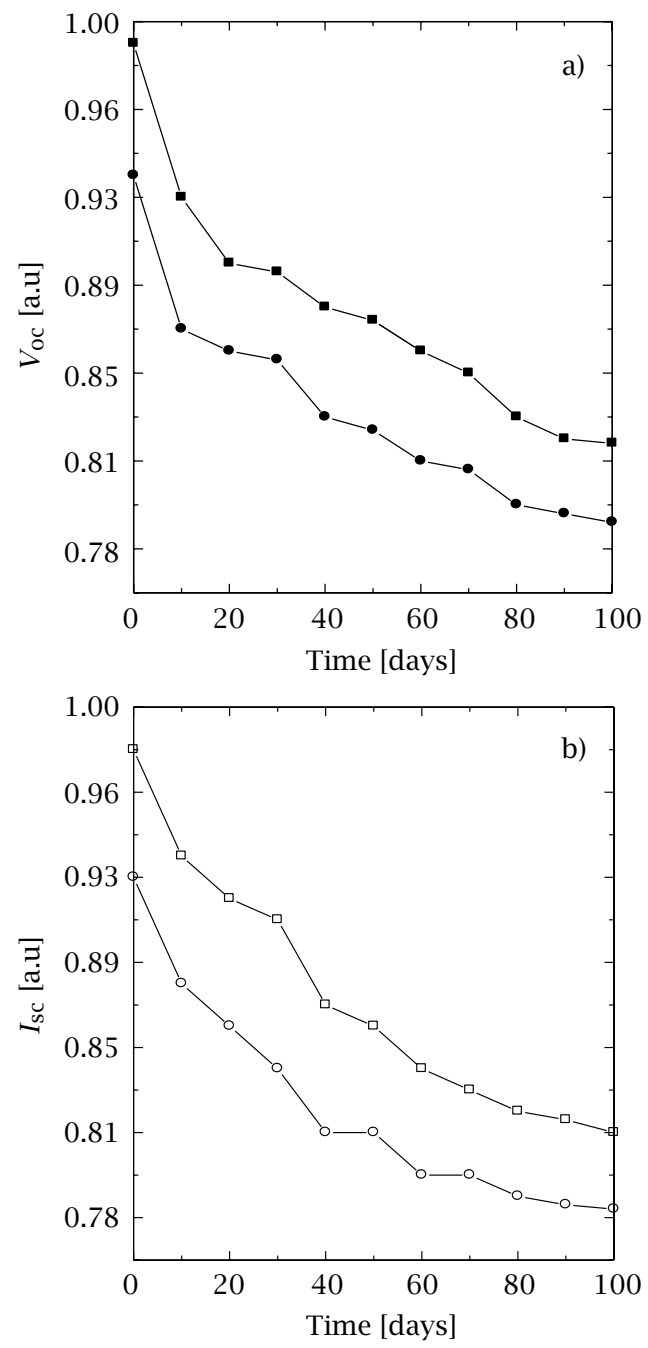

Figure 6. Comparison of the (a) $V_{\mathrm{OC}}$ (solid squares and solid circles) and (b) $I_{\mathrm{Sc}}$ (open squares and open circles) vs. shelf lifetime of two different strips of a $\mathrm{P} 3 \mathrm{OT} / \mathrm{C}_{60}$ protected plastic solar cells. 


\section{CONCLUSION}

The photovoltaic conversion efficiency of plastic solar cells based on conjugated polymer-fullerene bulk heterojunction is limited by the carrier collection efficiency (i.e. the separated charges must be collected with the minimum losses) and by charge transport. For photovoltaic devices fabricated from several blends of $\mathrm{P} 3 \mathrm{OT} / \mathrm{C}_{60}$ and its derivatives (PCBM mono and multiadducts), the highest open circuit voltage and short circuit current were obtained with blend of P3OT and PCBM monoadduct ( $1: 1$ weight ratio). In this work, the realized photovoltaic devices show power efficiency, $\eta_{\mathrm{e}}$ of $1.4 \%$ and an IPCE of about $20 \%$. We expect further improvements in device efficiencies by optimizing the composite composition, the network morphology and the charge transport properties of the individual components.

Unprotected plastic solar cells show current and voltage degradation under oxygen environment and light. Within the actual mixture used in plastic solar cells, the degradation rate of open circuit voltage, $V_{\text {oc }}$ is much slower compared to the short circuit current, $I_{\mathrm{sc}}$. This is proposed to arise from the increased trapping of the charge carriers due to degradation induced defects. Laminating and sealing the solar cells decreases the degradation rate, but it does not completely prevent degradation. Compared to unprotected plastic solar cells, cells protected against the influence of oxygen and humidity have increased shelf lifetime by at least a factor of 100. Our results indicate an increase of the overall serial resistivity by degradation. Large scale processing of solar cells from conjugated polymer/fullerene devices may become relevant for photoelectric energy conversion. A very important parameter for industrial applications is the lifetime of the devices. Stabilization of these composites is realized by the rigorous exclusion of oxygen.

\section{ACKNOWLEDGEMENTS}

This work was performed within the Christian Doppler Foundations dedicated Laboratory for Plastic Solar Cells. Further support by "Austrian Academic Exchange Service” (ÖAD) is gratefully acknowledged.

\section{REFERENCES}

[1] N. S. Sariciftci, L. Smilowitz, A. J. Heeger, and F. Wudl, Science 258 (1992), 1474.
[2] N. S. Sariciftci and A. J. Heeger, Handbook of Organic Conductive Molecules and Polymers (S. Halwa, H, ed.), vol. 1, Wiley, New York, 1997, p. 437.

[3] N. S. Sarciftci, D. Braun, C. Zhang, V. Srdanov, A. J. Heeger, G. Stucky, and F. Wudl, Appl. Phys. Lett. 62 (1992), 585.

[4] S. Morita, A. A. Zakhaidov, and K. Yoshino, Sol. State Commun. 82 (1992), 249.

[5] N. S. Sariciftci, Role of Buckminsterfullerene, $C_{60}$, in Organic Photoelectric Devices, J. Prog. Quant. Electr. 19 (1995), 131.

[6] J. Gao, H. Wang, and F. Hide, Synth. Met. 84 (1997), 979.

[7] G. Yu, J. Gao, J. C. Hummelen, F. Wundl, and A. J. Heeger, Science 270 (1995), 1789.

[8] S. C. Veenstra, G. G. Malliaras, H. J. Brouwer, F. J. Esselink, V. V. Krasnikov, P. F. van Hutten, J. Wildeman, H. T. Jonkman, G. A. Sawatzky, and G. Hadziioannou, Synth. Met. 84 (1997), 973.

[9] K. Yoshino, K. Tada, A. Fujii, E. M. Conwell, and A. A. Zakhidov, IEEE Trans Electron Dev. 44 (1997), 1315.

[10] J. J. M. Halls, C. A. Walsh, N. C. Greenham, E. A. Marseglia, R. H. Friend, S. C. Moratti, and A. B. Holmes, Nature 376 (1995), 498.

[11] G. Yu and A. J. Heeger, J. Appl. Phys. 78 (1995), 4510.

[12] C. J. Brabec, F. Padinger, J. C. Hummelen, R. A. J. Janssen, and N. S. Sariciftci, Proc. ICSM 98, Montpellier, France.

[13] M. Grangström, K. Petritsch, A. C. Arias, A. Lux, M. R. Andersson, and R. H. Friend, J. Nature 395 (1998).

[14] H. Neugebauer, C. J. Brabec, and N. S. Sariciftci, 1998, Submitted to Synth. Met.

[15] J. C. Hummelen, B. W. Wright, F. Lepec, and F. Wudl, J. Org. Chem. 60 (1995), 532.

[16] L. R. Roman, M. R. Anderson, T. Yohannes, and O. Inganäs, Adv. Mater. 9 (1997), no. 15, 1164.

[17] K. Yoshino, K. Tada, M. Hirohata, H. Kajii, Y. Hironaka, N. Tada, Y. Kaneuchi, M. Yoshida, A. Fijii, M. Hamagchi, H. Araki, T. Kawai, M. Ozaki, Y. Ohmri, M. Onoda, and A. A. Zakhidov, Synth. Met. 84 (1997), 477. 


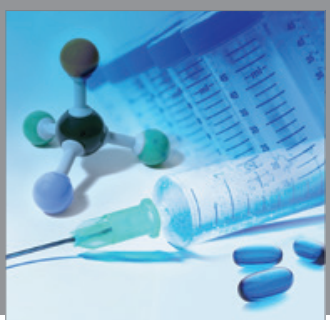

International Journal of

Medicinal Chemistry

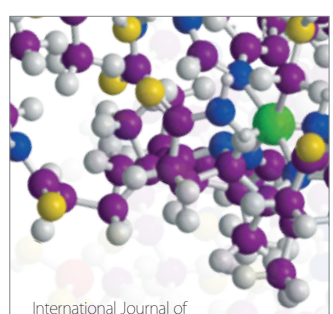

Carbohydrate Chemistry

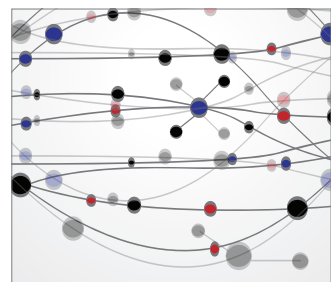

The Scientific World Journal
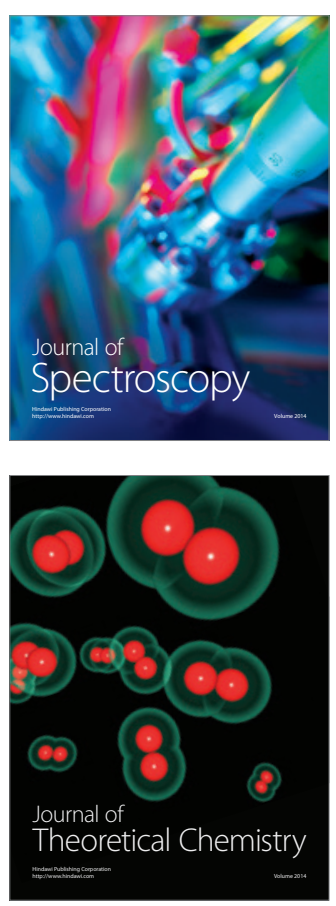
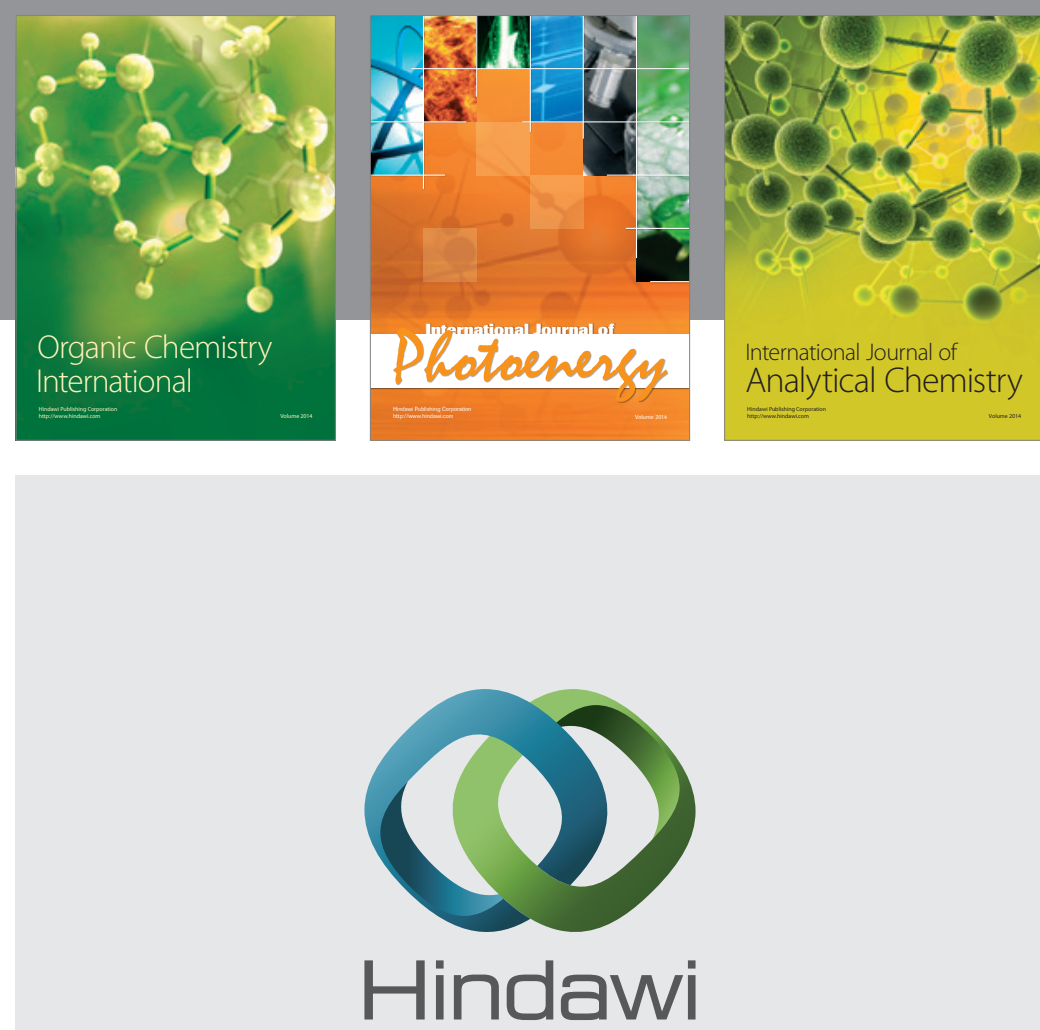

Submit your manuscripts at

http://www.hindawi.com
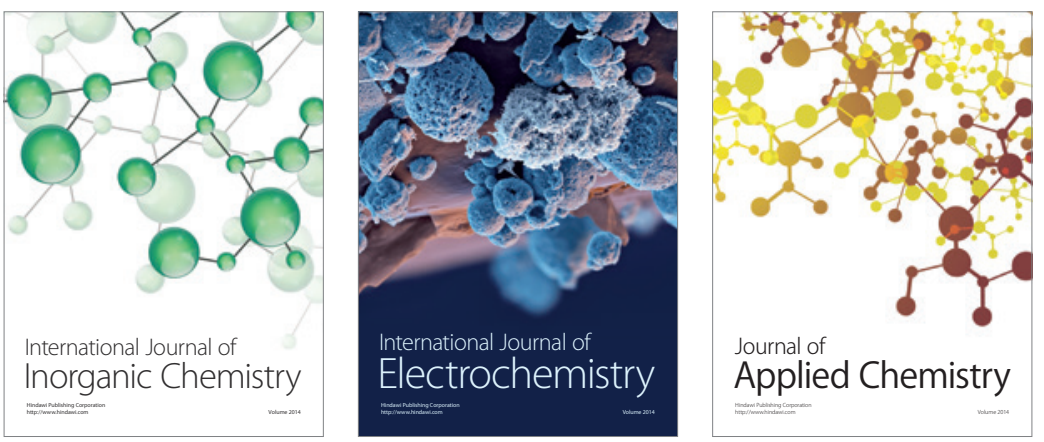

Journal of

Applied Chemistry
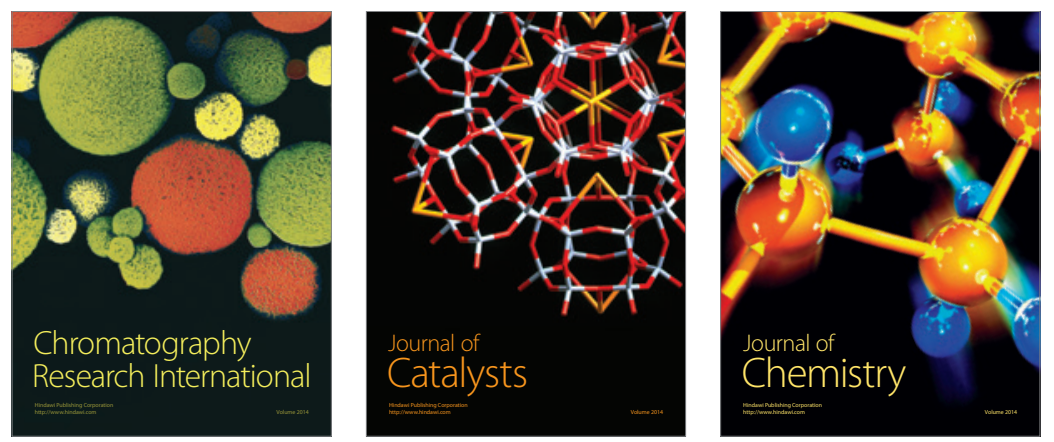
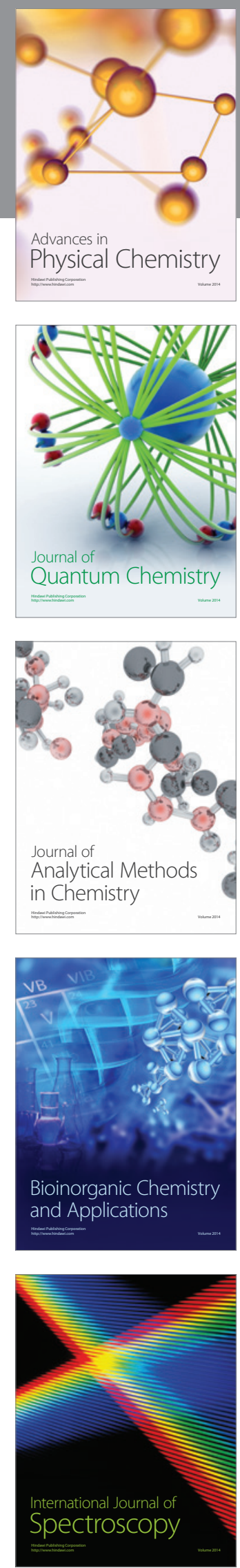